Check for updates

Cite this: RSC Adv., 2019, 9, 6228

Received 3rd January 2019

Accepted 5th February 2019

DOI: $10.1039 / c 9 r a 00051 h$

rsc.li/rsc-advances

\section{Tailoring the morphological features of sol-gel synthesized mesoporous hydroxyapatite using fatty acids as an organic modifier}

\author{
J. Anita Lett, (D) ${ }^{* a}$ M. Sundareswari, ${ }^{a}$ K. Ravichandran, ${ }^{b}$ M. Bavani Latha, ${ }^{c}$ \\ Suresh Sagadevan ${ }^{\star d}$ and Mohd. Rafie Bin Johan ${ }^{d}$
}

\begin{abstract}
Nowadays, owing to their large surface area, enhanced pore volume, increased porosity, and variable pore size, mesoporous materials, such as mesoporous silica and mesoporous carbon, have attracted significant attention in the areas of physical science and biomedical sciences. Due to their compositional and biological similarities to natural tissues, synthetic nanoscaled mesoporous hydroxyapatite (MPHA) nanoparticles possess good biocompatibility, bioactivity, and osteoconductivity and have recently expanded their applicability in a wide range of fields such as in tissue replacement, drug/gene delivery carriers, and biocompatible coatings. In this study, we defined a novel route to synthesize mesoporous hydroxyapatite nanoparticles by the sol-gel method in the presence of stearic acid (SA), a biocompatible medium chain fatty acid that would function as an organic modifier. The as-prepared HAP particles were subjected to structural, functional and morphological characterization. Mesopores in HAP were observed for samples synthesized at $\mathrm{pH} 11$ by removing the organic template. The porosity of HAP was confirmed by the Brunauer-Emmett-Teller (BET) analysis. The apatite deposition phenomenon in simulated body fluid at $\mathrm{pH} 7.4$ confirms their in vitro bioactivity, and based on the in vitro cytotoxicity examined using Vero cell cultures, the as-prepared HAP particles exhibit excellent cytocompatibility and cell viability as high as $83 \%$ at an extract concentration as low as $25 \%$. Moreover, the loading and leaching behavior of the drug in mesoporous HAP was studied using methionine (MT), an essential amino acid. These results confirm that nano mesoporous hydroxyapatite loaded with MT can be a potential aspirant as a biomaterial in biomedical applications.
\end{abstract}

\section{Introduction}

Calcium phosphate (CaP) materials, including hydroxyapatite (HAP), have attracted significant attention due to their biocompatibility, osteoconductivity, non-toxicity and capability to form an unswerving chemical bond with living tissues. ${ }^{1}$ HAP is also a prospective material for the reinforcing filler for composites due to its adaptability as an insulating agent for the easy and speedy fractionation of proteins and nucleic acids in tissue engineering. ${ }^{2,3}$ The high permanence of HAP in a wide choice of physical circumstances makes it an attractive material for implants. ${ }^{4}$ The use of CaP, particularly in the biomedical field, attracts significant attention due to its outstanding biocompatibility, biodegradability and $\mathrm{pH}$-responsive property.

\footnotetext{
${ }^{a}$ Department of Physics, Sathyabama Institute of Science and Technology, Chennai-600119, India. E-mail: janitalett17@gmail.com

${ }^{b}$ Department of Analytical Chemistry, University of Madras, Chennai-600025, India ${ }^{c}$ Department of Biotechnology, Sathyabama Institute of Science and Technology, Chennai-600119, India

${ }^{d}$ Nanotechnology \& Catalysis Research Centre, University of Malaya, Kuala Lumpur 50603, Malaysia.E-mail: drsureshnano@gmail.com
}

Thus, the synthesis of CaP with various morphologies, extensive variety of sizes, and hierarchical architecture is of practical value and also a requirement. ${ }^{5}$ HAP is a synthetic bone-like material with extensive bioactivity, biocompatibility, and osteoconductivity as compared to other porous materials, i.e., activated alumina, activated carbon and zeolites. ${ }^{6}$ In addition to the catalytic and environmental applications of HAP, the most explored and described area of the applications of HAP is biomedicine. ${ }^{7,8}$

Predominantly, mesoporous hydroxyapatite (MPHA) with a high surface-volume ratio and adsorption capability is always associated with having enhanced abilities. Amongst the existing synthesis methods used in the preparation of HAP, the sol-gel is considered a promising technique due to the lesser equipment used, higher output and also due to its ease in operation. ${ }^{9}$ The morphology and spreading behavior of the synthesized particles can be influenced by the addition of organic modifiers during the precipitation process. Quite a lot of studies in the literature have investigated the behavior of surfactants such as sodium citrate, ${ }^{\mathbf{1 0}}$ cetyltrimethylammonium bromide (CTAB), ${ }^{\mathbf{1 1}}$ sodium dodecyl sulfate (SDS), and polyoxyethylene sorbitan monolaurate as organic modifiers. ${ }^{12}$ Zhang HG et al. ${ }^{13}$ using glutamic 
acid as the modulator, prepared mesoporous hydroxyapatite nanoparticles with ribbon-like morphology. Researchers have also used various polymers such as polyvinyl alcohol (PVA), ${ }^{14}$ polyacrylic acid (PAA), ${ }^{15}$ polyethylene glycol (PEG) ${ }^{16}$ etc. to control the morphology or to afford a pattern for the synthesis of hydroxyapatite nanoparticles. Recently, researchers have focused on green synthesis using non-toxic natural sources such as carbohydrates, proteins, fibres, polysaccharides peptides, as well as nucleic acids and fatty acids as templates for the synthesis of nanoparticles. ${ }^{17,18}$ Thus, mesoporous hydroxyapatite with features similar to those of biological apatite can be attained using these resources, making them ideal for bone tissue engineering practices. In understanding the shapecontrolled synthesis, fatty acids as a template for synthesis permit simplistic separation among the nucleation and growth stages; therefore, the tuning of crystal growth is effortlessly approachable so that the morphology can be controlled. The role of the surfactant in defining the morphology needs a distinct indication on the account of its capability to adhere to specific crystal facets and direct crystal growth. ${ }^{19}$

Sumatra M. et al. recommended that the template synthesis by fatty acids altered the crystallinity and morphology of the nanomaterials. The changes in the crystallinity can be entirely attributed to the changes in the morphology of the materials, and lower crystallinity promotes improved biological activity. ${ }^{18}$ Amongst the fatty acids, SA is widely used as a surface modifier in the manufacturing of calcium carbonate and as a crystal modifier in the development of calcium phosphates. SA is biocompatible and can be expelled from the body after decomposition into $\mathrm{H}_{2} \mathrm{O}$ and $\mathrm{CO}_{2}$ by the metabolic system. Thus, it can be seen that stearic acid seems to be a good possible candidate for use as a surface modifier for calcium phosphate fillers. ${ }^{20}$ The general functional group of carboxyl in fatty acids can promote the binding of calcium ions $\left(\mathrm{Ca}^{2+}\right)$ from the solution of carboxylate ions, helping in the formation of mesoporous HAP and thus promoting size-controlled morphology. ${ }^{20,21}$ Out of the essential amino acids, methionine (MT) is one among the important sulfur donors. MT is also used in the biosynthesis of proteins, an important cartilage-forming substance, and is crucial for numerous physical and biological progressions in organisms. In addition, MT supplementation or limiting can interfere in the normal antioxidant capability of an organism by aiding in the formation of endogenous enzymes that reduce oxidative stress and, in turn, pave the path for DNA damage, the development of cancer cells, heart diseases, neuropsychiatric disorders, and neurodegenerative diseases. MT cannot be prepared by the body and thus must be consumed in food, as its deficiency causes arthritis. ${ }^{19}$

Herein we have used a fatty acid, SA as an organic template to form MPHA. The presence of the carboxyl group present in SA in the reaction mixture could have caused its absorption on the surface of HAP, which resulted in the formation of narrow distribution pores in the surface of the HAP sample during the process of autoclaving. Thus, the adsorbed carboxyl group likely caused the formation of micropores in the HAP nanorods as they were formed. MT, one among the essential amino acids, was used as a drug to study its leachabilities. To our knowledge, we haven't read of any MPHA syntheses using fatty acids. Hence, this work aims to investigate the structural and morphology behavior of HAP synthesized using stearic acid as an organic modifier. Finally, the bioactivity, cell adhesion/ proliferation/toxicity and drug leaching behavior of MT-loaded MPHA were also explored.

\section{Materials and methodology}

\subsection{Materials}

All the reagents including analytical-grade calcium nitrate tetrahydrate $\left(\mathrm{Ca}\left(\mathrm{NO}_{3}\right)_{2} \cdot 4 \mathrm{H}_{2} \mathrm{O}\right)$, diammonium hydrogen phosphate $\left(\left(\mathrm{NH}_{4}\right)_{2} \mathrm{HPO}_{4}\right)$, ammonium hydroxide $\left(\mathrm{NH}_{3} \cdot \mathrm{H}_{2} \mathrm{O}\right)$ and stearic acid, were purchased from Sigma-Aldrich. The cell line was obtained from Madras Veterinary College, Chennai-7, Tamil Nadu.

\subsection{Synthesis of HA-LA}

The schema for the synthesis of HAP by the sol-gel method is shown in Fig. 1. In brief, according to previous work, ${ }^{22,23} 1 \mathrm{~mol}$ calcium nitrate tetrahydrate made in $100 \mathrm{~mL}$ of ethanol and $100 \mathrm{~mL}$ of $0.6 \mathrm{M}$ aqueous diammonium hydrogen phosphate was added dropwise to the calcium solution. Then, 25\% ammonia solution $\left(\mathrm{NH}_{4} \mathrm{OH}\right)$ was added dropwise until precipitation occurred to form a milky white solution followed by vigorous stirring; the solution was maintained at $\mathrm{pH} 11$. The addition of mild base $\mathrm{NH}_{4} \mathrm{OH}$ with $\mathrm{NaOH}$ makes no alteration in the reaction, but the addition of urea to the calcium phosphate solutions can slowly raise the solution $\mathrm{pH}$ to a value in which that HAP is insoluble while heating. Meanwhile, $\mathrm{CO}_{2}$ was produced through the decomposition of urea; thus, the apatite is likely to integrate $\mathrm{CO}_{3}$ in the lattice and support the synthesis of calcium-deficient apatite $\left(\mathrm{CO}_{3} \mathrm{HAP}\right){ }^{24}$ The modification of HAP structure was accomplished by the introduction of bulky or asymmetric assemblies on the polymer support or on the amalgamation of noncoplanar structural units of the main polymer chain. ${ }^{25}$ The polymers are generally derived from substituted aromatic bisazomethine diols exhibiting a high degree of crystallinity, which induces very low solubility. ${ }^{26}$ The organic modifier SA, $\left(\mathrm{CH}_{3}\left(\mathrm{CH}_{2}\right)_{16} \mathrm{COOH}\right)$ was added, and the

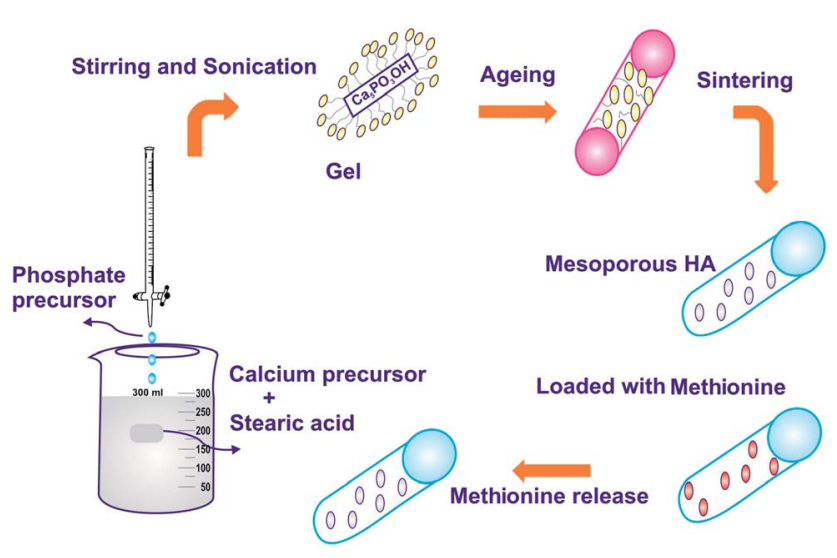

Fig. 1 Schematic of the synthesis and drug release of HAP. 
solution was sonicated in a sonicator maintained at $30 \mathrm{kHz} \pm$ $50 \mathrm{~Hz}$ frequency with an operating voltage of $100 \mathrm{~W}$ for a period of $24 \mathrm{~h}$ to undergo gelation. The structure modified gel was oven dried at $100{ }^{\circ} \mathrm{C}$ to evaporate the excess ethanol that was used as a solvent. The final resulting precipitate was then washed with double distilled water, oven-dried at $100{ }^{\circ} \mathrm{C}$ for $24 \mathrm{~h}$ and further calcinated in a muffle furnace at $800{ }^{\circ} \mathrm{C}$ for $2 \mathrm{~h}$. The experiment was repeated by varying the $\mathrm{pH}$ of the solution to $\mathrm{pH} 7$ and 9, respectively, while maintaining the concentration of SA at the critical micelle concentration (CMC - $1 \mathrm{mM}$ ). Finally, the samples were finally sintered at $800{ }^{\circ} \mathrm{C}$ to remove the organic phase and the desired crystalline MPHA was obtained.

\subsection{Bioactivity assessment}

The assessment of bioactivity was carried out by standard in vitro procedures using analytical reagent-grade chemicals $\mathrm{NaCl}$, $\mathrm{NaHCO}_{3}, \mathrm{KCl}, \mathrm{K}_{2} \mathrm{HPO}_{4} \cdot 3 \mathrm{H}_{2} \mathrm{O}, \mathrm{MgCl}_{2} \cdot 6 \mathrm{H}_{2} \mathrm{O}, \mathrm{CaCl}_{2}$, Tris-buffer, $\left[\mathrm{CH}_{2}(\mathrm{OH})_{3} \mathrm{CNH}_{2}\right]$, and $1 \mathrm{M} \mathrm{HCl}$. Typically, MT-loaded MPHA in the form of pellets of $5 \mathrm{~mm}$ diameter were immersed in a cellular SBF at a concentration of $0.01 \mathrm{~g} \mathrm{~mL}^{-1}$ in a clean glass beaker rinsed with $\mathrm{HCl}$ and deionized water. The beakers were placed inside a thermostatic incubator at a temperature of $34{ }^{\circ} \mathrm{C}$ for 7 days while maintaining a $\mathrm{pH}$ of 7.4. Throughout the period of immersion, the SBF solutions were not refreshed. The viability of the apatite nucleation and deposition were accomplished through FESEM attached with EDX.

\subsection{Drug loading and release investigation}

Normally, $0.5 \mathrm{~g}$ of the MPHA powder was mixed evenly with $0.5 \mathrm{mg}$ of MT drug dissolved in water and was then pressed into pellets. The average weight for each sample was recorded using a tabulating machine, since all the experiments were done in triplicate. The MPHA pellet loaded with $0.5 \mathrm{mg}$ of MT, was transferred into $100 \mathrm{~mL}$ of dissolution medium consisting of a freshly prepared phosphate buffer saline, maintained at $37{ }^{\circ} \mathrm{C}$ and stirred at the rate of $100 \mathrm{rpm}$. Three-milliliter aliquots were withdrawn at predetermined time intervals for all the batches and their absorbance (207 nm) was observed. For each sample withdrawn, an equivalent volume of phosphate buffer was added to the dissolution medium to ensure perfect sink conditions. The release profiles of all the batches were measured for 7 days (168 h), and the absorbance was recorded by a spectrophotometer. The amount of MT released was calculated using the eqn (1).

$$
\text { Drug released }(\%)=\frac{\text { amount of drug released }(\mathrm{mg})}{\text { total amount of drug loaded }(\mathrm{mg})} \times 100
$$

\subsection{Cell adhesion/proliferation/toxicity test}

The cell cytotoxicity/adhesion/proliferation of Vero cell activity on MT-MPHA (methionine-mesoporous hydroxyapatite) was respectively investigated by MTT assay using phase contrast microscopy analysis. The MTT [3-(4,5-dimethyl thiazol-2-yl)-2,5diphenyltetrazolium bromide] assay, measuring cellular metabolic activity, under defined conditions reflects the number of viable cells (cell proliferation). Tetrazolium dye assays may also be used to measure the cytotoxicity (loss of viable cells) or cytostatic activity (shift from proliferative to resting status) of potential medicinal agents and their toxic materials. ${ }^{13,27}$ Briefly, cells were seeded in 96-well plates at $1 \times 10^{5}$ cell per well at the

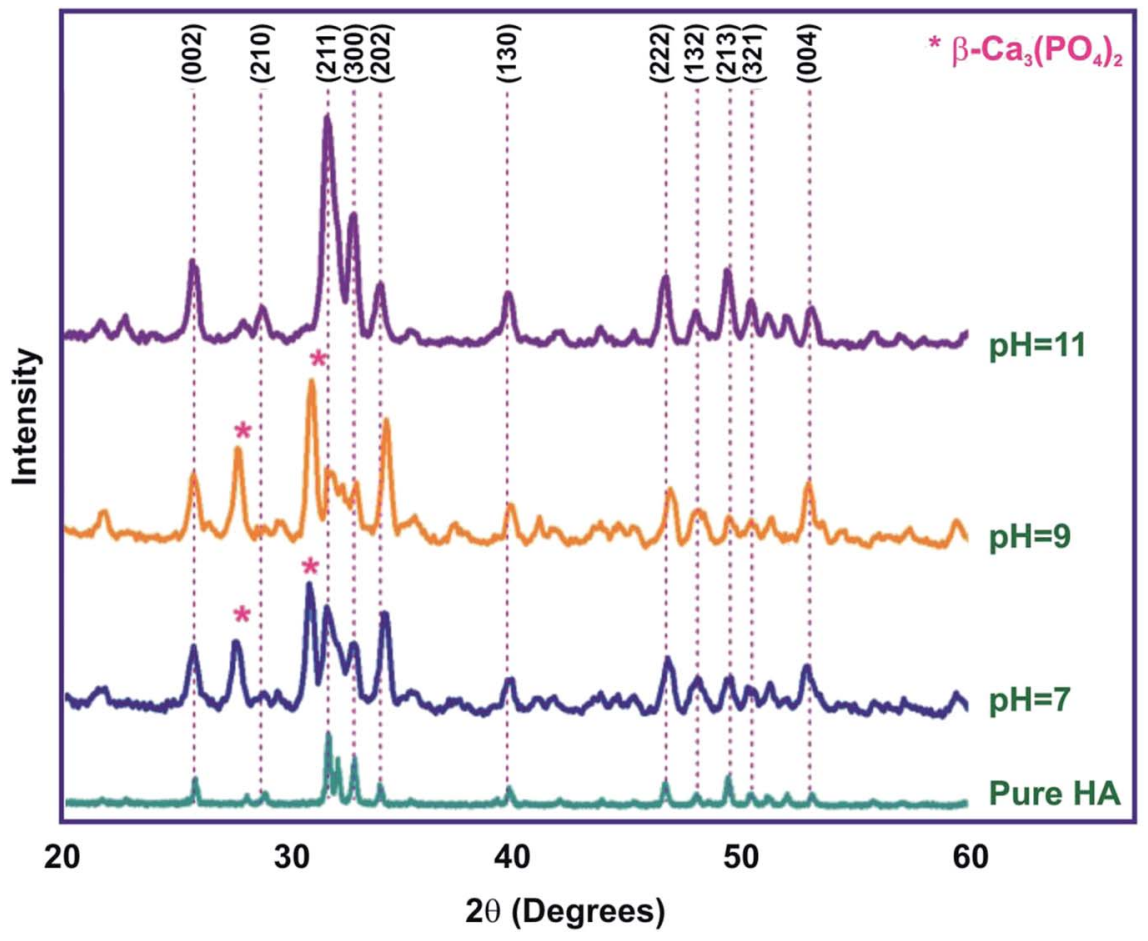

Fig. 2 XRD of HAP synthesized by the sol-gel method for different $\mathrm{pH}$ (7, 9 and 11). 
Table 1 Crystallite size and the percentage of crystallinity of HAP

\begin{tabular}{lllll}
\hline $\begin{array}{l}\text { Sol-gel } \\
\text { synthesis, pH }\end{array}$ & $\begin{array}{l}\text { Concentration } \\
\mathrm{mM}\end{array}$ & $\begin{array}{l}\text { Crystallite } \\
\text { size }(\mathrm{nm})\end{array}$ & $X_{\mathrm{c}}(\%)$ & $\mathrm{Ca} /$ P ratio \\
\hline pH 11 & - & 44 & 2.392 & 1.68 \\
pH 7 & 1 & 11 & 1.749 & 1.602 \\
pH 9 & 1 & 11 & 1.757 & 1.55 \\
pH 11 & 1 & 10 & 1.799 & 1.68
\end{tabular}

time intervals of 0 and $24 \mathrm{~h}$ post-seeding. The cell culture medium was replaced with $300 \mu \mathrm{L}$ fresh MEM medium containing 4, 8, 16, 32, 64, 125, 250 and $500 \mu \mathrm{g} \mathrm{mL} \mathrm{m}^{-1}$ of MT-HA nanoparticles. The cell viability (OD) at $24 \mathrm{~h}$ on the scaffold was quantified by adding $20 \mu \mathrm{L}$ of MTT solution $\left(5 \mathrm{mg} \mathrm{mL}^{-1}\right.$ in PBS) to each well and incubating for $4 \mathrm{~h}$. Then, $180 \mu \mathrm{L}$ of DMSO was added to neutralize the crystals formed during the addition of MTT. The values of the solution were measured using an ELISA reader (Bio-Rad) at a wavelength of $450 \mathrm{~nm}$. The cell monolayer of the seed specimen was examined microscopically for the response around the test samples using a phase contrast microscope (Olympus $40 \times$ ).

\subsection{Characterization techniques}

2.6.1. Physiochemical characterization. The crystallinity and phase purity of the calcined MPHA was determined by a Philips X'pert Pro diffractometer, Schmadzo, (Netherlands) using nickel-filtered $\mathrm{Cu} \mathrm{K}_{\alpha}$ radiation $\left(k_{\alpha}=1.5406 \AA\right)$. The functional group identification of the MPHA powder was carried out using a single-beam Fourier transform infrared spectrometer (Agilent, Cary 630) using the $\mathrm{KBr}$ pellet technique in the spectral wavelength range of 4000 to $650 \mathrm{~cm}^{-1}$. The surface area and pore size distribution of the prepared samples were determined using Brunauer-Emmett-Teller (BET) specific surface area and a pore size distribution analyzer (Autosorb-iQ2MP, Quantachrome).

2.6.2. Morphological characterization. Morphological characterization was performed using field emission scanning electron microscopy (FESEM: Supra VP35 Carl Zeiss, Germany) and high-resolution transmission electron microscopy (FETEM: FEI-TECNAI G2-200 KV TWIN). The elemental composition analysis was obtained by energy dispersive X-ray (EDX: X-Max, USA) spectra with a standard unit (Oxford Instruments, UK) attached to the FESEM.

\section{Results and discussion}

\subsection{XRD analysis}

The diffraction patterns of the sintered HAP samples, synthesized with and without SA at different $\mathrm{pH}(7,9,11)$, are shown in Fig. 2. Phase analysis was performed using PDF card no. 009-0432 for HAP and 29-0359 for $\mathrm{Ca}_{3} \mathrm{PO}_{4}$ ( $\beta$-TCP), providing information in the $2 \theta$ range of $20-60^{\circ}$. For HAP synthesized without SA, all the diffraction patterns of the synthesized samples are in good agreement with those of the standard HAP crystallites, revealing characteristic peaks at $2 \theta$ $=25.9^{\circ}(002), 2 \theta=31.7^{\circ}(211), 2 \theta=32.1^{\circ}(112), 2 \theta=32.8^{\circ}$ (300), $2 \theta=46.6^{\circ}(222)$ and $2 \theta=49.4^{\circ}$ (213), which are well compatible with (JCPDS no. 9-0432). ${ }^{28}$ The critical micelle concentration of stearic acid was fixed as $1 \mathrm{mmol}$ according to previous studies in literature. ${ }^{29}$ Of the three samples synthesized at different $\mathrm{pH}$, the diffraction peaks of the sample synthesized at $\mathrm{pH} 11$ correspond to the formation of purephase HAP according to JCPDS card no. 9-0432, whereas the samples synthesized with SA at pH 7 and 9 show an additional peak at $31.02^{\circ}$, suggesting that a small amount of $\beta$-TCP might

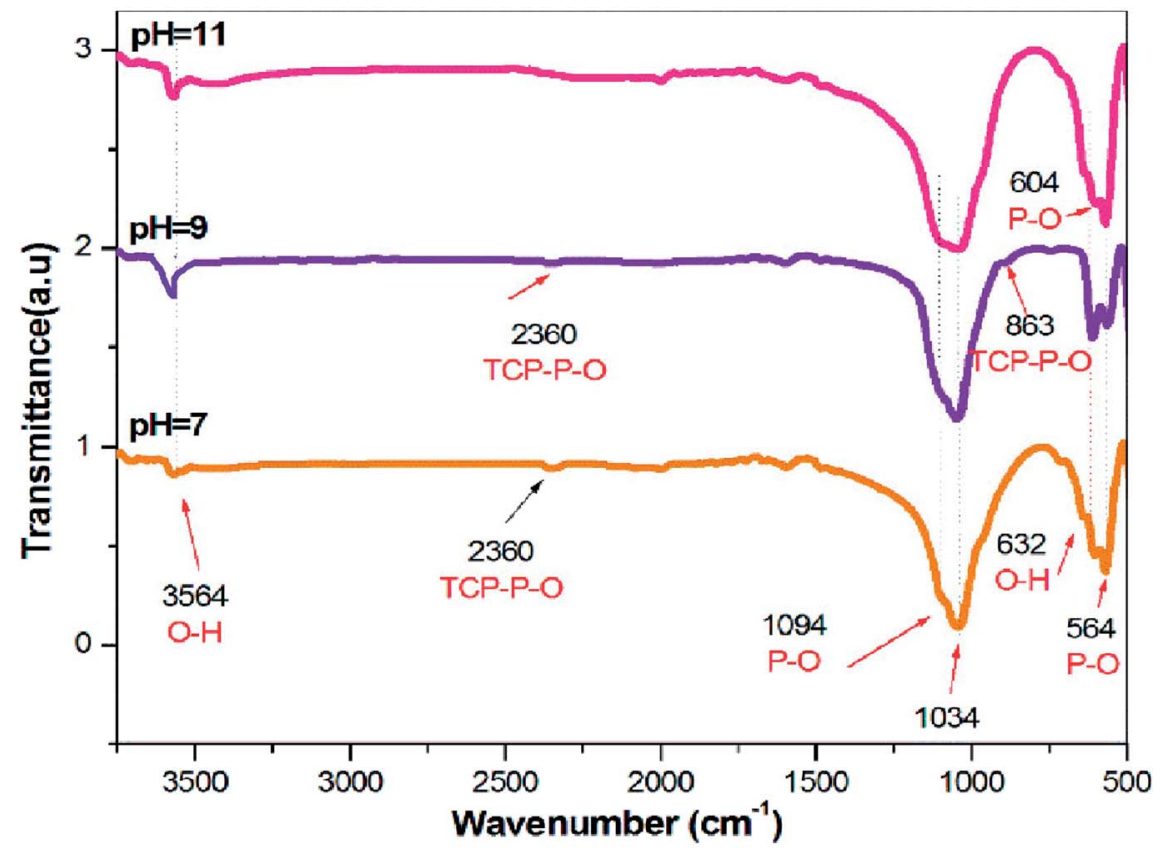

Fig. 3 FTIR of HAP synthesized via the sol-gel method for different $\mathrm{pH}(7,9$, and 11). 
be formed as a contamination phase along with HAP. It is to be noted that the intensity of the $\beta$-TCP peak corresponding to $31.02^{\circ}$ and $27.7^{\circ}$, increases with intensity as the $\mathrm{pH}$ is increased from 7 to 9 and completely vanishes when the $\mathrm{pH}$ is further increased to $\mathrm{pH} 11$. These observations finally suggest that the $\mathrm{pH}$ is an essential requirement for the sol to obtain phase-pure apatite and that the ideal $\mathrm{pH}$ for HAP precipitation is at $\mathrm{pH}$ 11. The presence of broad peaks reveals the occurrence of smaller-sized particles, compared to samples prepared without SA. ${ }^{30}$ The presence of SA in the precipitation of HAP has a strong influence in the particle size. The average crystallite size of the HAP samples calculated using DebyeScherrer's equation is given in Table 1 .
The crystallite size $D_{h k l}$ and the degree of crystallinity $\left(X_{\mathrm{c}}\right)$ was calculated based on the previous studies ${ }^{11}$ as follows,

$$
\begin{gathered}
D_{h k l}=\frac{k \lambda}{\beta \cos \theta} \\
X_{\mathrm{c}}=1-\left(\frac{0.24}{\beta}\right)^{3}
\end{gathered}
$$

where $K=0.94$ is a constant, $\lambda$ is the wavelength of monochromatic radiation $\left(\lambda=1.5405 \mathrm{~A}^{\circ}\right)$, and $\beta$ is defined as the diffraction peak for full width at half maximum. From Table 1, the strong decrease in the crystallinity and crystallite size of the as-synthesized HAP using SA is clearly indicated. This was

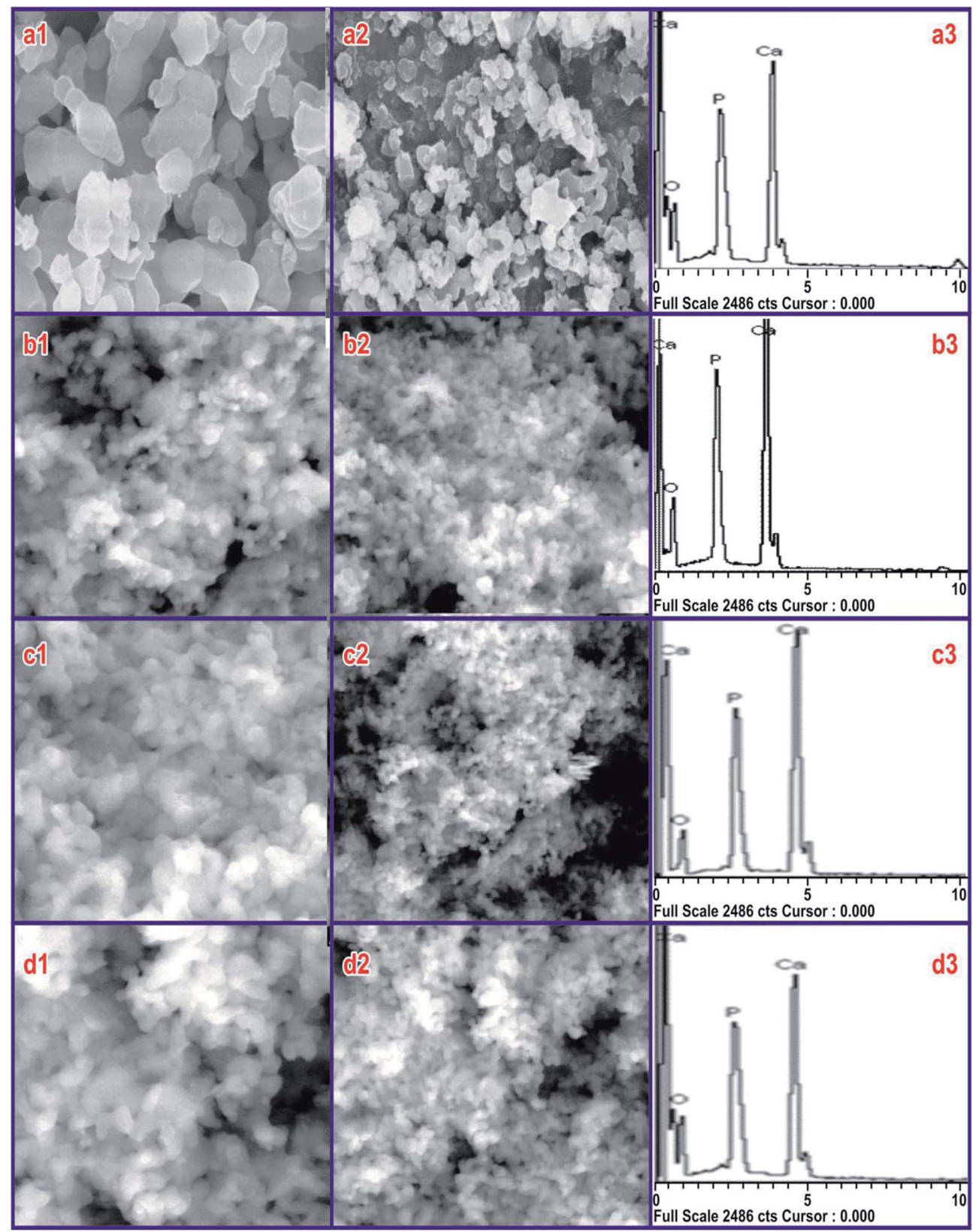

Fig. 4 SEM image and EDX pattern of the samples synthesized at (a) pure HAP without SA and at (b) pH 7, (c) pH 9, and (d) pH 11 in the presence of SA $(C M C)$ with HAP. 


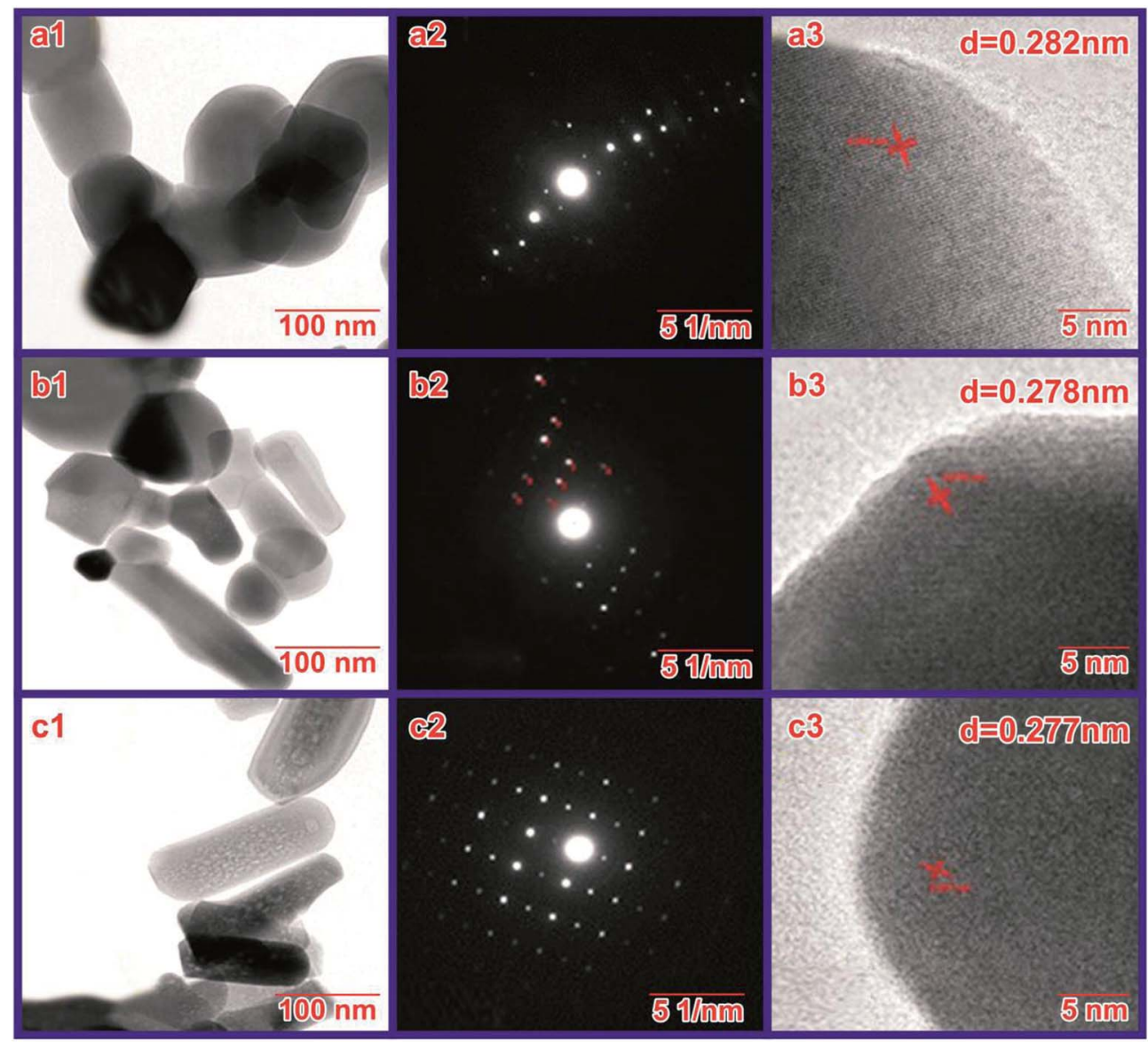

Fig. 5 HRTEM image at a magnification of $0.5 \mu \mathrm{m}$ and diffraction pattern of the samples synthesized at (a) $\mathrm{pH}$ 7, (b) $\mathrm{pH} 9$, and (c) pH 11 .

verified by the calculated crystallite size and crystallinity according to Scherrer's equation. The diffraction peak at $26^{\circ}$ corresponding to the (002) plane was considered for the calculation of crystallite size and crystallinity as it was an isolated sharp peak. From the XRD measurements, it was verified that, for HAP nanoparticles prepared in the absence of SA, the fraction of crystallinity was $2.32 \%$ for crystallites $44 \mathrm{~nm}$ in size. Whereas, for the HAP nanoparticles synthesized with SA at pH 11 , the fraction of crystallinity was $\sim 1.8 \%$ for crystallites $10 \mathrm{~nm}$ in size. Normally, for biomedical applications, HAP particles of low crystallinity were desirable due to their high in vivo resorbable property. ${ }^{31}$ Hence, the addition of $1 \mathrm{mM}$ of SA at $\mathrm{pH}$ 11 had a considerable effect on refining the purity in addition to lowering the crystalline nature of the as-synthesized HAP nanoparticles.

\subsection{FTIR analysis}

FTIR spectroscopy is an analytical technique generally used to describe the functional groups existing in biomaterials such as HAP. Theoretically, there are four vibrational modes $\left(v_{1}, v_{2}, v_{3}\right.$, and $U_{4}$ ) for phosphate ions present in the apatite structure, all of which are IR active. The IR spectra of the HAP samples synthesized in the presence and in the absence of SA are presented in Fig. 3. The broad FTIR band centered around 1000$1100 \mathrm{~cm}^{-1}$ is the primary symbol of the development of HAP. ${ }^{32}$
Besides, the peaks around $3564 \mathrm{~cm}^{-1}$ and $632 \mathrm{~cm}^{-1}$ are the characteristic peaks of the $\mathrm{OH}$ group of HAP, allocated due to the free $\mathrm{O}-\mathrm{H}$ stretching mode, that might exist on the surface of the crystallites. ${ }^{33}$ The peaks found at 1094 and $1034 \mathrm{~cm}^{-1}$ were qualified to the triply degenerate asymmetric stretching vibration $\left(U_{3}\right)$ mode of the major phosphate group. ${ }^{34}$ No bands were formed around $1422 \mathrm{~cm}^{-1}$, indicating the absence of carbonate groups in the FTIR spectra of all the synthesized samples. The peaks found at 604 and $564 \mathrm{~cm}^{-1}$ were caused by the doubly degenerate bending mode $\left(\mathrm{U}_{4}\right)$ of the P-O bond. Thus, all the peaks found in this spectrum strongly confirm the formation of HAP. The presence of TCP is also evidenced by the stretching frequency of the phosphate group at 863 and $2360 \mathrm{~cm}^{-1}$ for the samples synthesized in $\mathrm{pH} 7$ and 9. Furthermore, the existence of TCP is weakened, as the $\mathrm{pH}$ was decreased from 9 to 7 . Thus, at $\mathrm{pH} 11$ in the presence of SA, the HAP peaks were only detected without any other $\mathrm{Ca}-\mathrm{P}$ impurities, as evidenced in Fig. 3, whereas, for samples synthesized at $\mathrm{pH} 7$ and 9, traces of TCP were confirmed. Also, FT-IR results clearly indicate that SA functional groups were not incorporated in the sintered HAP samples.

\subsection{FESEM analysis}

To screen the influence of SA on HAP particles at CMC, the morphology at different $\mathrm{pH}$ was recorded using SEM, and its 
Table 2 Average pore size and BET surface area of the prepared mesoporous HAP with a fatty acid

\begin{tabular}{lrl}
\hline $\begin{array}{l}\text { Sol-gel } \\
\text { synthesis, pH }\end{array}$ & \multicolumn{1}{c}{$S_{\text {BET }}\left(\mathrm{m}^{2} \mathrm{~g}^{-1}\right)$} & $\begin{array}{l}\text { Average pore } \\
\text { size }(\mathrm{nm})\end{array}$ \\
\hline pH 7 & $7.7138 \pm 0.0474$ & - \\
pH 9 & $10.5197 \pm 0.0399$ & - \\
pH 11 & $66.265 \pm 0.0345$ & 5.86
\end{tabular}

EDX records are shown in Fig. 4 for $40 \mathrm{k}$ and 80k times magnification of the sample. The SEM micrographs of the sample synthesized at $800{ }^{\circ} \mathrm{C}$ in the absence of SA (Fig. 4(a1 and a2)) shows larger particles aggregated particles, whereas those synthesized in the presence of SA show uniform morphology in all HAP samples. From the FESEM micrographs, obviously, the synthesized compounds are uniform in size and highly aggregated, which are formed in large quantities. A combination of calcium phosphate phases was observed for HAP prepared at pH 7 and 9. Micro-sized rectangular crystals were seen in the prepared samples at a $\mathrm{pH} 7$, which was made out of HAP with traces of $\beta$-TCP, as found in Fig. 4 (b1 and b2). Upon further increasing the $\mathrm{pH}$ to 9 , the rectangular crystal structure changed to a sponge-like structure, as seen in Fig. 4(c1 and c2). This structure was also comprised of HAP with traces of $\beta$-TCP. In both cases, the $\mathrm{pH}$ value was lower, and accordingly, the formation rate of HAP was very poor. ${ }^{35}$ The samples synthesized at $\mathrm{pH} 11$ indicated infantile particles developing in one direction as well as an increased rate of HAP formation, shown in Fig. 4(d1 and d2). The HAP granules combined to shape microorganism-like nanostructures. Besides, the compositional changes and response conditions, i.e., precursors, temperature, time, $\mathrm{pH}$, solvent, pressure, and ligands all showed an essential role in the stability of various phosphate phases. ${ }^{36,37}$ It is important to note that the microstructure of HAP is fundamentally the same as that of the normal bone. EDX was used to examine various components and their composition present in the sample. The typical EDX spectra of HAP are shown in Fig. 4(a3, b3, c3 and d3). The spectra indicate the occurrence of $\mathrm{Ca}, \mathrm{P}$, and $\mathrm{O}$ as the major elements along with the elemental spectra. No traces of other elements in the spectra confirm that the prepared samples are pure in form, but the EDX analysis shows that highly stoichiometry HAP (1.68) can be obtained at pH 11 in SA at the CMC concentration. For samples synthesized at $\mathrm{pH} 7$ and 9, the stoichiometric ratio was found to be 1.602 and 1.55, which could be due to the presence of traces of TCP present in the sample during the synthesis process.

\subsection{HRTEM analysis}

The size and morphology of the prepared HAP nanostructures sintered at $800{ }^{\circ} \mathrm{C}$ were determined by TEM observations. The TEM images of HAP synthesized with SA at pH 7, 9 and 11 are shown in Fig. 5(a1, b1 and c1). The HAP sample synthesized

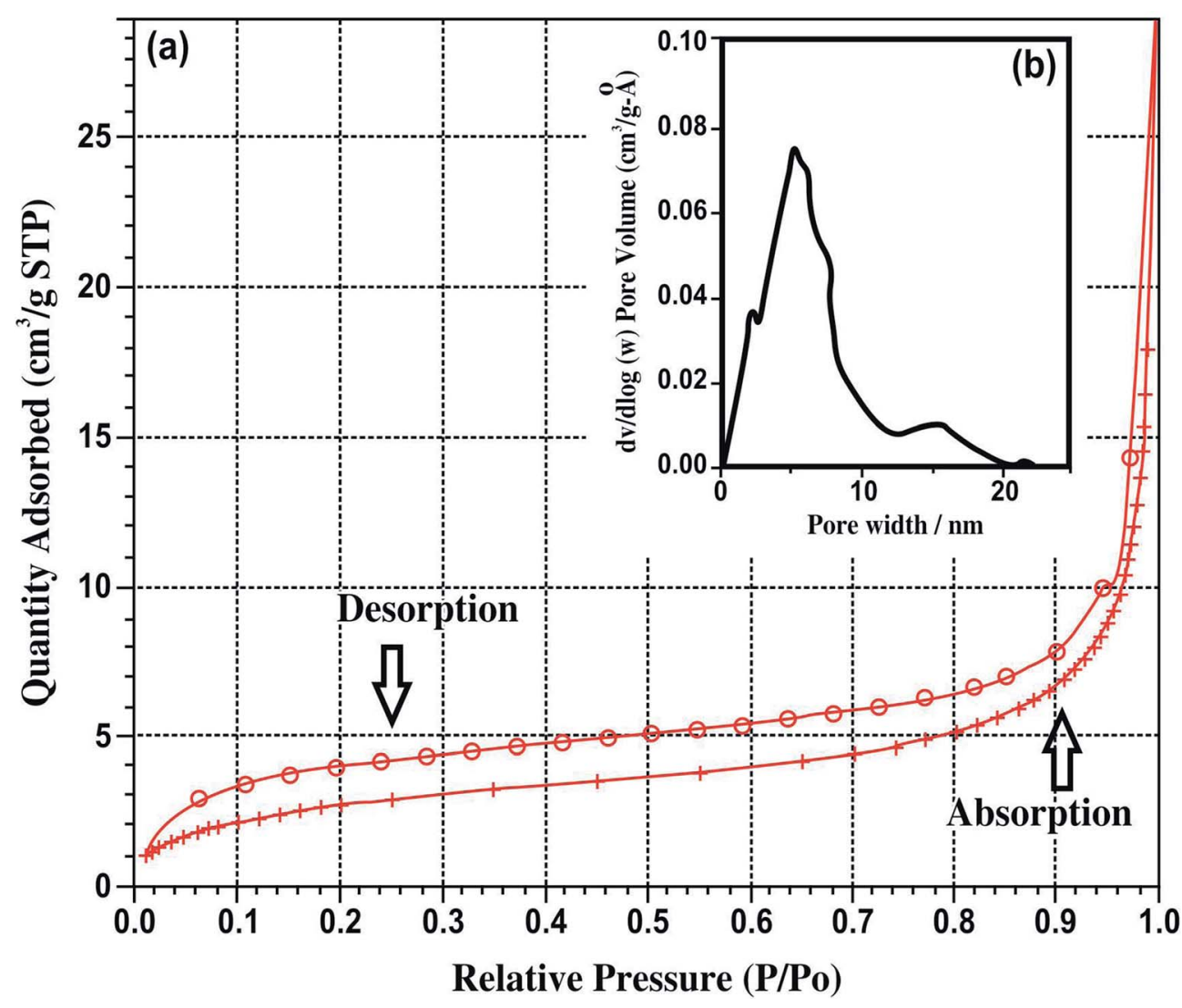

Fig. 6 (a) Nitrogen adsorption-desorption isotherms and (b) pore size distribution of HAP synthesized at pH 11. 

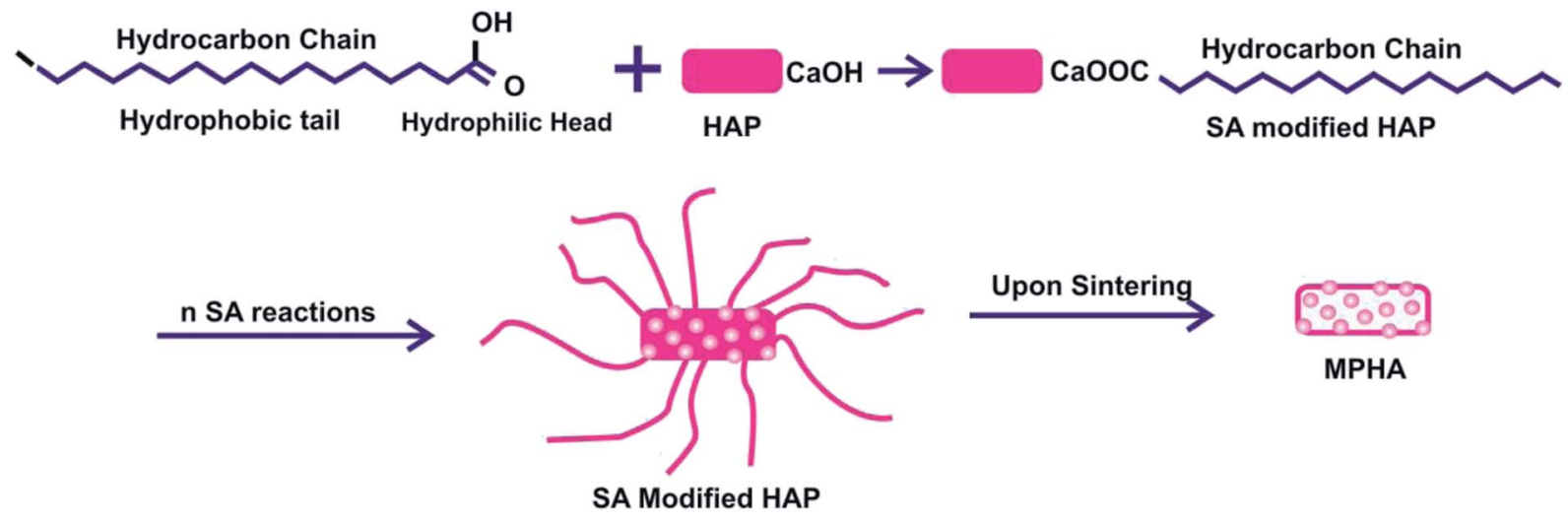

Fig. 7 The schematic represents the formation of MPHA in the presence of SA.

using SA clearly shows non-agglomerated elongated particles. The shape, size, and length of nanorods synthesized at $\mathrm{pH} 11$ are much improved compared with those synthesized with SA at pH 7 and 9. Thus, the HAP synthesized using SA at pH 11 was found to be rod-like particles without agglomeration, and a close look at the morphology shows nanometer pores that are poorly crystalline in nature. The sintering temperature/time likewise plays an important role in the constituents and microstructure of the synthesized HAP.

Zanotto et al. showed that highly pure phase HAP with wellordered assembly can be preserved up to $900{ }^{\circ} \mathrm{C}$ by rod-shaped particles with higher crystallinity. The growth of size with temperature takes place with the growth of the particles in a uniaxial direction (facets with fewer OH-concentrations). The possible nanoneedle nucleation and growth to the successive rod could be attributed to the absolute specific superficial energies, which determine the $\mathrm{OH}$-quantity, related to the diverse facets of the HAP crystal. The particle morphology changes in the uniaxial direction (facets with less $\mathrm{OH}_{-}$ concentration) upon raising the temperature. Similarly, the size of the HAP particle grows with the rise in temperature, which has been contributed to variation in the concentration of $\mathrm{Ca}$ and $\mathrm{CO}_{3}{ }^{2-}$ ions, $\mathrm{pH}$, etc. Upon further increasing the temperature, the morphology of HAP nanoparticles changes from rod-shaped to spherical. ${ }^{38}$

Some of the organic modifiers such as citric acid, ethylenediamine tetraacetic acid, and trisodium citrates, Tween 20, and polyethylene glycol MW 600, cetyltrimethylammonium bromide (CTAB) were shown to control the size, shape, morphology and pores of the HAP particles during their synthesis. ${ }^{39-41}$ Though many water-soluble organic compounds and aqueous extract of many plants have been used as a green chelating agent to modify the surface of the hydroxyapatite nanoparticles, such nanoparticles are also produced in various fascinating shapes and evaluated for various applications. For the first time, we have used SA, a water-insoluble compound, to produce MPHA nanorods. This is the first report added in the field of organic modifiers of the production of HAP mesoporous nanorods with well-defined shapes.

Thus, we conclude that SA concentration and solution $\mathrm{pH}$ play a crucial role in preventing agglomeration and in controlling crystal morphology with mesopores and desired stoichiometry during synthesis. TEM images and the selected area diffraction (SAED) pattern of synthesized HAP nanoparticles are depicted in Fig. 5(a, b and c), respectively. Fig. 5(b) confirms that the SAED patterns of the prepared samples show diffraction rings rather than individual spots, representing the polycrystalline nature of the prepared samples. Fig. 5(c) shows the typical high-resolution TEM image, which displays clear and well-defined lattice fringes of the prepared HAP. The calculated spacing between two lattice fringes is $0.277 \mathrm{~nm}$, corresponding to the (211) plane of hexagonal hydroxyapatite. The well-defined lattice fringes again confirmed that the synthesized HAP has high-crystalline structures, as affirmed previously.

\subsection{Porosity measurement}

According to BET results, the BET surface area and average pore size of HAP synthesized at pH 7, 9 and 11 are given in Table 2 . The related nitrogen adsorption-desorption isotherms and the corresponding Barrett-Joyner-Halenda (BJH) pore size distribution is presented in Fig. 6(a) and (b). In the study, using SA to guide the formation of mesoporous HAP, several observations were found, such as the presence of SA in the reaction causing

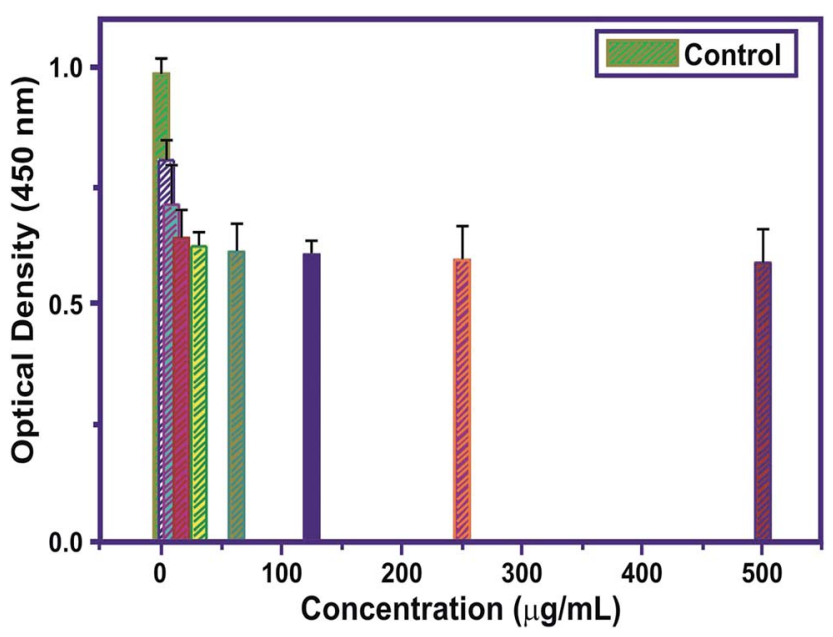

Fig. 8 The O.D. value of MT-HAP for various concentrations of MT. 

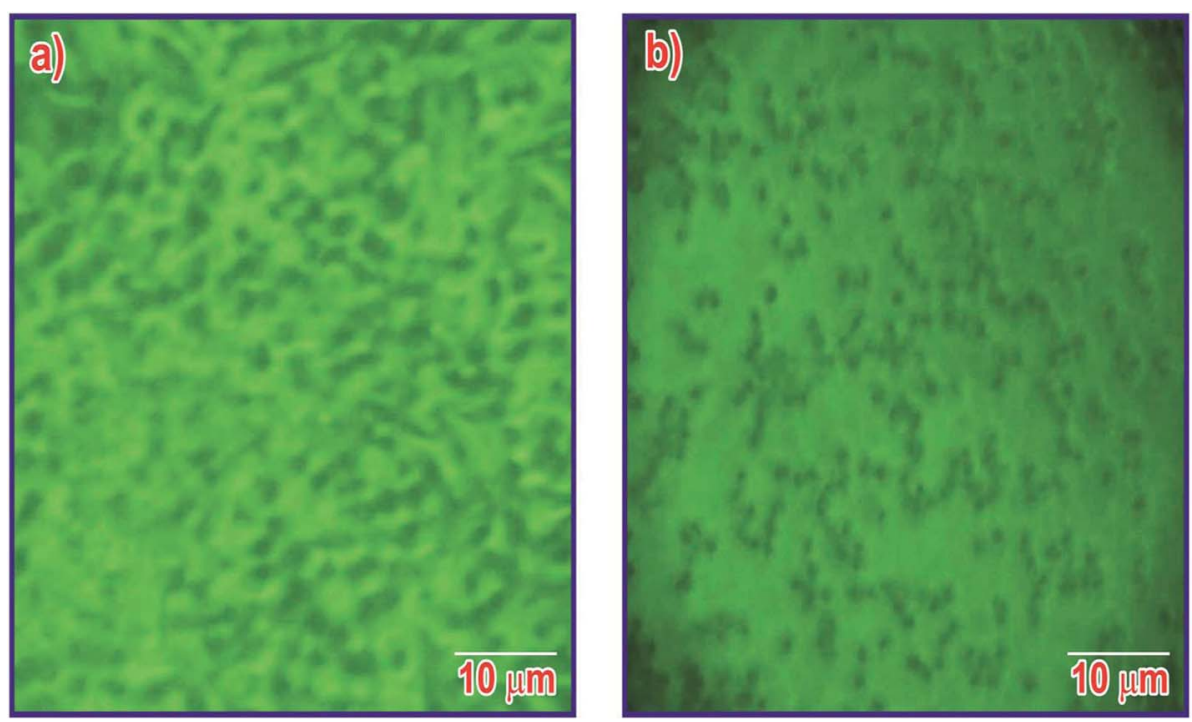

Fig. 9 Phase-contrast microscopy images of the seeded Vero cell lines (a) initially and (b) the cells after 24 hours.

no impurities to form for the sample synthesized at $\mathrm{pH} 11$. The formed HAP has a crystal size of $10.312 \mathrm{~nm}$ with a crystallinity of $1.799 \%$. The resulting HAP has a mesoporous structure; the pore size was estimated to be $5.86 \mathrm{~nm}$. It was found that for only the sample synthesized at $\mathrm{pH} 11$, mesopores with a pore volume of $5.86 \mathrm{~nm}$ was observed to have a larger BET surface area of $66.265 \pm 0.0345 \mathrm{~m}^{2} \mathrm{~g}^{-1}$, whereas the other samples did not process any porosity. Thus, the surface area was much smaller, with values of $7.7138 \pm 0.0474$ and $10.5197 \pm 0.0399$, respectively.

The kinetics of the formation of hydroxyapatite modified by stearic acid (SA) and the formation of a chemical reaction between HAP and SA is as follows.

$$
\begin{aligned}
\mathrm{Ca}_{9}\left(\mathrm{PO}_{4}\right)_{6} \mathrm{OH} \cdot \mathrm{CaOH}+\mathrm{C}_{17} \mathrm{H}_{33} \mathrm{COOH} \rightarrow & \rightarrow \mathrm{Ca}_{9}\left(\mathrm{PO}_{4}\right)_{6} \mathrm{OH} \cdot \mathrm{CaC}_{17} \mathrm{H}_{33}+\mathrm{H}_{2} \mathrm{O}
\end{aligned}
$$

The chemical reaction of SA with HAP leads to the formation of a chemical bond.

The amino acid, SA has a hydrophilic head with the functional group $\mathrm{COOH}$ and a hydrophobic tail with a series of hydrocarbon chains. Initially, the hydrophilic head, the carboxyl group $-\mathrm{COOH}$, can interact randomly and bond with the $\mathrm{Ca}^{2+}$ ions in the HAP to form a complex (Fig. 7).

Thus, the HAP surface is functionalized with SA molecules. As the aspect ratio increases, a number of SA molecules attach themselves onto the surface of the HAP molecule, leading to the formation of a rod-like missile. As the HAP is sintered, the hydrocarbons chains bonded with the molecules decomposed leaving behind nanopores. Thus, MPHA with a pore size of around $5.86 \mathrm{~nm}$ were achieved using SA as an organic modifier at $\mathrm{pH} 11 .^{20}$

\subsection{Cell adhesion/proliferation/toxicity test on MT-HAP}

Cytotoxicity studies are robust studies and, in recent years, were considered as one of the most important factors for the development of new bone substitutes. Interestingly, some materials which were known to be inert, are in fact toxic in large quantities at the nanoscale. Employing such types of nanoparticles, which are toxic in nature over a longer period of time, could significantly diminish the therapeutic efficiency of cell-based
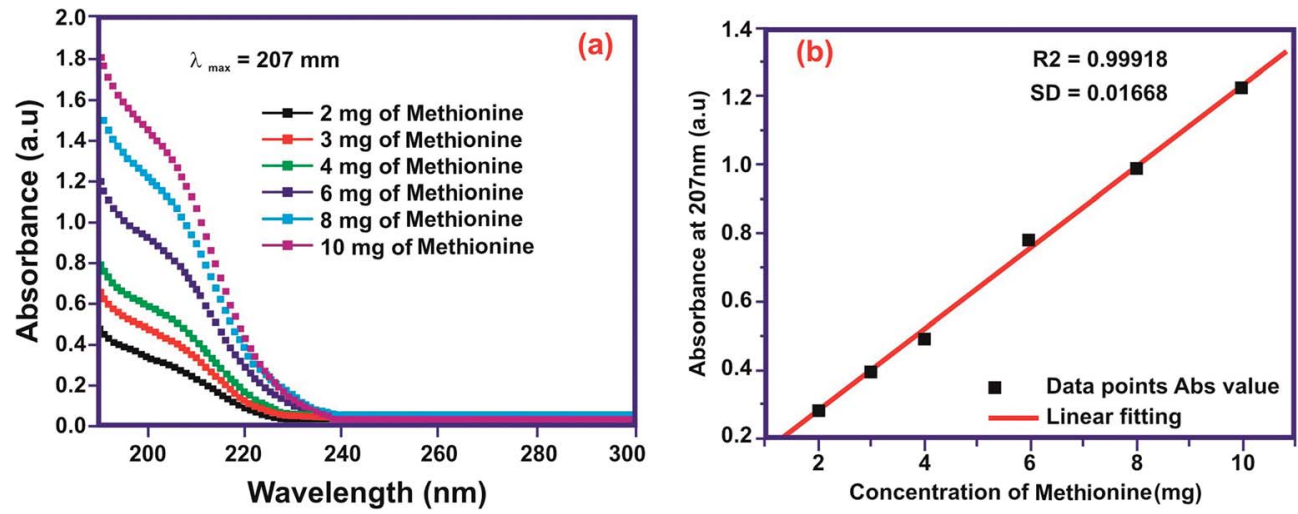

Fig. 10 (a) ME absorption curves for the standard concentration and (b) the calibration graph. 


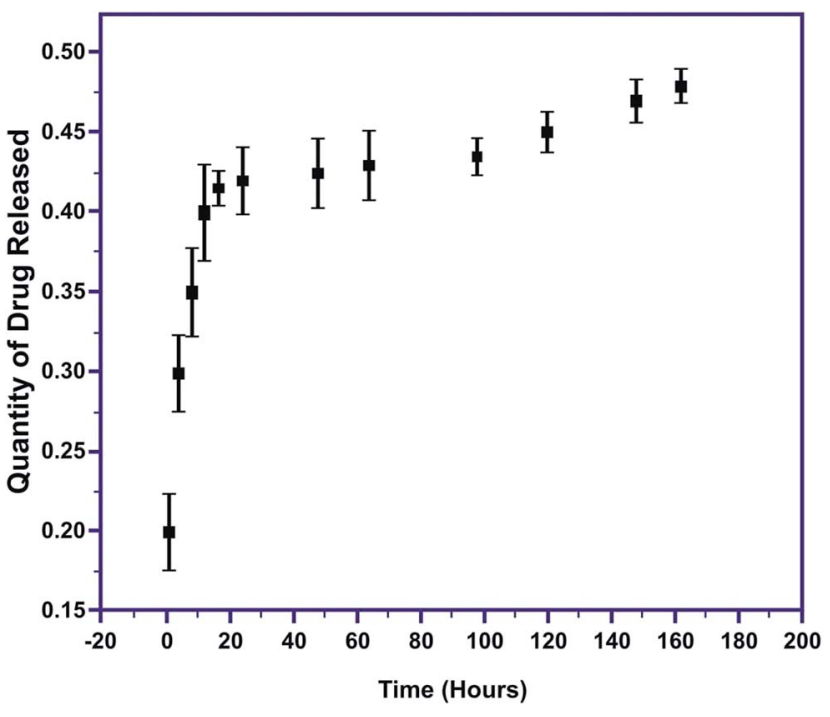

Fig. 11 Amount of drug released with time.

therapy. The structural properties, dosage, and chemical composition of the particles lead to the toxicity of the nanoparticles on the biological entities. ${ }^{42,43}$ In this study, the cytotoxicity of MT-MPHA prepared using SA were investigated. Fig. 8 shows the dependence of the O.D. value on MT-MPHA dispersion for various concentrations of MT. The O.D. value indicates the percentage of viable cells. The VERO cells seeded initially serve as the control group, which is considered $99 \%$ viable. As expected, the cell viability decreases with increasing concentration of MT-MPHA after a day culture. Notably, it is important to mention that, at the MT-MPHA extract concentrations of $12.5 \%$ and $25 \%$, more than $70 \%$ of the cells are mitochondrially viable. The phase contrast microscope image of the Vero cells after treating the samples for $24 \mathrm{~h}$ is shown in Fig. 9(a). From Fig. 9(b), it is clear that the morphology was not affected, and the MTT assay reveals at most identical cell morphology, viability with respect to control, which indicates that the compounds do not show any cytotoxic effects and that similar globular shaped cells were observed. It was found that the lowest concentrations of $4 \mu \mathrm{g} \mathrm{mL} L^{-1}$ and $16 \mu \mathrm{g} \mathrm{mL} L^{-1}$ showed $90 \%$ and $74 \%$ cells, which were mitochondrially viable after a one-day incubation period. The $\mathrm{IC}_{50}$ value of MT-MPHA was 63 $\mu \mathrm{g} \mathrm{mL}^{-1}$. Similar results were observed in Bioinspired YSZ coated with NIH3T3 fibroblast cells. ${ }^{44}$ Different kinds of dendrimers (Zinger, Capsaicin) were also prepared for cytotoxic assays used for biomedical applications. ${ }^{45}$ These findings suggest that the MT-HAP composites synthesized show good biocompatibility and that these MT-MPHA composites should be biologically safe materials for the drug, since the concentration of the carrier materials used in the drug is usually below $100 \mu \mathrm{g} \mathrm{mL}^{-1}$. Anyway, further trials are also needed within the in vivo biocompatibility assays.

\subsection{Drug leaching studies}

The contest of nanomedicine over other predictable tools for biomedical disciplines in the diagnosing, treating and thwarting of diseases has enhanced our knowledge in refining human health and hygiene. ${ }^{46}$ Polymers comprising conjugated $\mathrm{CH}-\mathrm{N}$ bonds on the main backbones have involved substantial attention over the past decade due to their diverse applications in numerous areas. ${ }^{47} \mathrm{~A}$ calibration curve for the standard concentration of the drug is very important in analyzing the discharge rate of the drug from nanoparticles in an appropriate medium. ${ }^{48} \mathrm{~A}$ known concentration $\left(2-10 \mathrm{mg} \mathrm{mL}^{-1}\right)$ of MT was scanned using a UV-visible spectrophotometer. For MT having a concentration in the range of $2-10 \mathrm{mg} \mathrm{mL} \mathrm{m}^{-1}$, a prominent peak at $207 \mathrm{~nm}$ was noticed. The absorbance values at $207 \mathrm{~nm}$ obtained with the respective concentration were noted, and a standard calibration graph was plotted (Fig. 10(a)). With the help of this calibration curve (Fig. 10(b)), the unknown concentration of ME was obtained by knowing the absorbance value of the drug for a particular period.

The quantity of MT released was evaluated as a function of time in PBS at 7.4 pH. The initial burst of MT released within

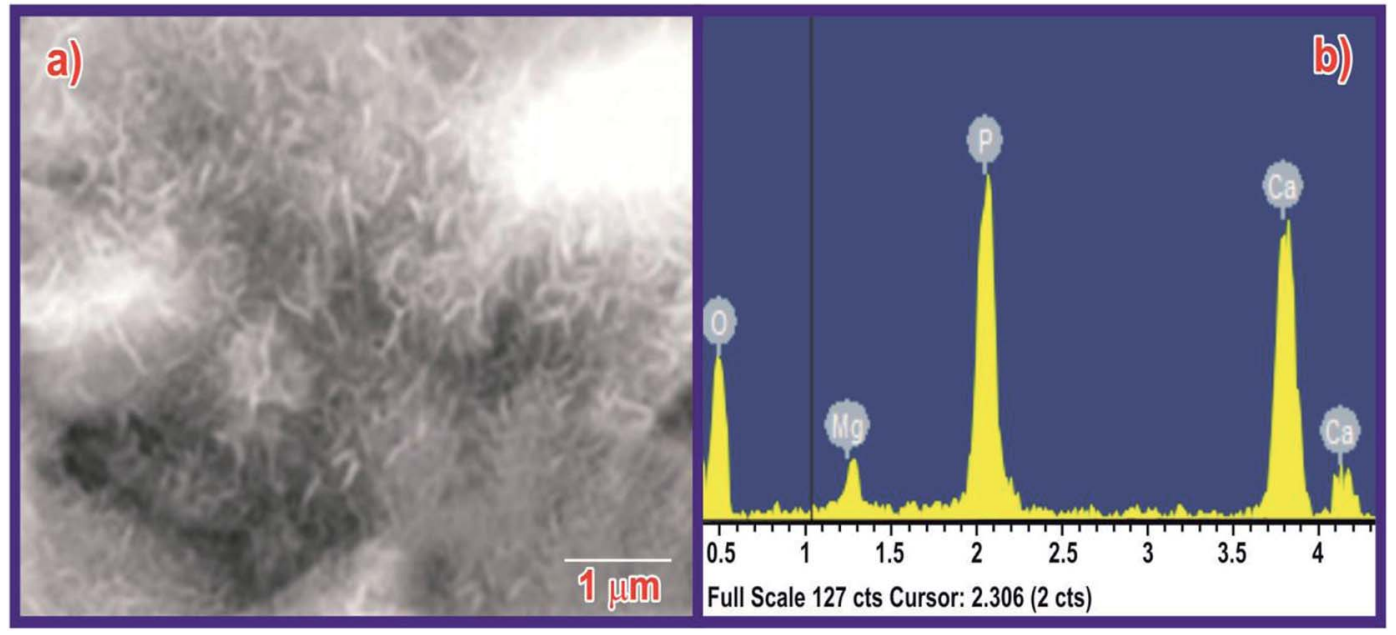

Fig. 12 (a) SEM image and (b) EDX of MPHA. 
the first 60 minutes was 0.2147 to $0.281 \mathrm{mg} \mathrm{mL}^{-1}$ and gradually decreased to $0.0097 \mathrm{mg} \mathrm{mL}^{-1}$ at the end of the 164 hours (Fig. 11). Thus, a very sudden and rapid release of nearly $80 \%$ of the drug occurred during the first 12 hours of the immersion of the pellet, followed by the slow release of the remaining $20 \%$ of the drug. The initial speedy release is accredited to the initial high difference in the drug concentration gradient between the pellet and the release medium. This explosive release of the drug is beneficial for speedy recovery. ${ }^{49,50}$ These results confirm complete MT release from the MT-MPHA pellets.

\subsection{The bioactivity assessment}

The bioactivity of the MPHA pellets was evaluated by immersing the scaffolds in SBF for seven days; apatite had almost completely colonized on the surface of the scaffold (Fig. 12). Traces of magnesium were found in the EDX data after immersion for 14 days in SBF. Thus, the synthesized scaffolds are highly bioactive. The EDX pattern of the immersed sample shows traces of magnesium mineral in the apatite.

\section{Conclusions}

Mesoporous rod-like nano-crystalline HAP particles have been successfully prepared by sol-gel synthesis in the presence of stearic acid as an organic modifier. The obtained results illustrate that the nonionic surfactants can also promote and control the growth of HAP particles at higher $\mathrm{pH}$. The strong interactions between the dissolved SA in ethanol medium lead to the formation of well-defined cylindrical micelles that act as stencils for the nucleation and growth of rod-like HAP particles. The XRD results of HAP nanoparticles synthesized with SA at $\mathrm{pH} 11$ exhibited $\sim 1.8 \%$ crystallinity (poorly crystalline in nature) for crystallites $10 \mathrm{~nm}$ in size, desirable for biomedical applications due to their higher resorbable property. The FTIR results infer pure phase HAP at pH 11 without any other $\mathrm{Ca}-\mathrm{P}$ impurities. HRTEM and EDX analysis confirm highly stoichiometric, rodlike morphology without agglomeration. Thus, the size of the hydroxyapatite crystals can be controlled in the presence of water-insoluble fatty acids and stearic acid by controlling the $\mathrm{pH}$ of the reaction during sol-gel synthesis. A pH of 11 was suitable for the production of mesopores with a pore volume of $5.86 \mathrm{~nm}$ and a corresponding BET surface area of $66.265 \pm$ $0.0345 \mathrm{~m}^{2} \mathrm{~g}^{-1}$. The MT drug loading demonstrated an initial burst release followed by the slow release of the drug, which is beneficial for the speedy recovery of tissues. The apatiteforming capability in simulated body fluid solution confirms the in vitro bioactivity and in vitro cytotoxicity, and the Vero cell culture exhibits excellent cytocompatibility and cell viability as high as $83 \%$ at an extract concentration as low as $25 \%$. These outcomes show that MPHA generated using stearic acid could be a useful material for bone tissue engineering.

\section{Conflicts of interest}

The authors declare no conflict of interest.

\section{Acknowledgements}

This work was supported by DST-FIST under project number (SR-FIST-PSI-193-2014). The Department of Physics at the Sathyabama Institute of Science and Technology provided the facilities used for characterization. One of the authors (Suresh Sagadevan) acknowledges the honor, namely the "Senior Research Fellow," granted at the Nanotechnology \& Catalysis Research Centre (NANOCAT), University of Malaya 50603 Kuala Lumpur, Malaysia. The author wishes to place on record his heartfelt thanks that are due to the authorities concerned.

\section{References}

$1 \mathrm{M}$. Vallet-Regi and J. M. Gonzalez-Calbet, Calcium phosphates as substitution of bone tissues, Prog. Solid State Chem., 2004, 32, 1-31.

2 A. A. Chaudhry, H. X. Yan, K. Gong, F. Inam, G. Viola, M. J. Reece, J. B. M. Goodall, I. u. Rehman, F. K. McNeilWatson, J. C. W. Corbett, J. C. Knowles and J. A. Darr, High-strength nanograined and translucent hydroxyapatite monoliths via continuous hydrothermal synthesis and optimized spark plasma sintering, Acta Biomater., 2011, 7, 791-799.

3 V. M. Rusu, C. H. Ng, M. Wilke, B. Tiersch, P. Fratzl and M. G. Peter, Size-controlled hydroxyapatite nanoparticles as self-organized organic-inorganic composite materials, Biomaterials, 2005, 26, 5414-5426.

4 C. L. Cardoso, C. Curra, P. L. Santos, M. F. M. Rodrigues, O. Ferreira-Junior and P. S. P. de Carvalh, Current considerations on bone substitutes in maxillary sinus lifting, Rev. Clin. Periodoncia Implantol. Rehabil. Oral, 2016, 9(2), 102-107.

5 X. Ma, W. Peng, S. Wen, Y. Zeng, G. Chen, X. Chen, B. Guo and X. Li, Delicate Assembly of Ultrathin Hydroxyapatite Nanobelts with Nanoneedles Directed by Dissolved Cellulose, Inorg. Chem., 2018, 57(8), 4516-4523.

6 C.-H. Ooi, Y. Pei Ling, S.-Y. Pung and F.-Y. Yeoh, Mesoporous hydroxyapatite derived from surfactant-templating system for p-Cresol adsorption: physicochemical properties, formation process, and adsorption performance, Powder Technol., 2019, 342, 725-734.

7 J. Kamieniak, A. M. Doyle, P. J. Kelly and C. E. Banks, Novel synthesis of mesoporous hydroxyapatite using carbon nanorods as a hard-template, Ceram. Int., 2017, 43, 54125416.

8 A. Haider, S. Haider, S. Soo Han and I.-K. Kang, Recent advances in the synthesis, functionalization and biomedical applications of hydroxyapatite: a review, $R S C$ Adv., 2017, 7, 7442.

9 I. S. Kim and P. N. Kumta, Sol-gel synthesis and characterization of nanostructured hydroxyapatite powder, Mater. Sci. Eng., B, 2004, 111, 232-236.

10 X. Jin, J. Zhuang, Z. Zhang, et al., Hydrothermal synthesis of hydroxyapatite nanorods in the presence of sodium citrate and its aqueous colloidal stability evaluation in neutral pH, J. Colloid Interface Sci., 2015, 443, 125-130. 
11 N. K. Nga, N. T. Thuy Chau and P. H. Viet, Facile synthesis of hydroxyapatite nanoparticles mimicking biological apatite from eggshells for bone-tissue engineering, Colloids Surf., $B, 2018,172,769-778$.

12 S. Amin, T. Siddique, M. Mujahid, S. S. Shah and A. D. Anjum, Synthesis of Nano Hydroxyapatite Ceramic Powders Using Different Surfactant Templates and Their Characterization, Nucleus, 2011, 48, 35-40.

$13 \mathrm{H}$. G. Zhang and Q. S. Zhu, Glutamic acid-mediated synthesis of ultra-long hydroxyapatite nanoribbons under hydrothermal conditions, Chem. Lett., 2005, 34, 788-789.

14 K. Xue, S.-H. Teng, N. Niu and P. Wang, Biomimetic synthesis of novel polyvinyl alcohol/hydroxyapatite composite microspheres for biomedical applications, Mater. Res. Express, 2018, 5, 115401.

15 C. Qiu, X. Xiao and R. Liu, Biomimetic synthesis of spherical nano-hydroxyapatite in the presence of polyethylene glycol, Ceram. Int., 2008, 34, 1747-1751.

16 H. Zhang, M. Liu, H. Fan and X. Zhang, An efficient method to synthesize carbonated nano-hydroxyapatite assisted by poly (ethylene glycol), Mater. Lett., 2012, 75, 26-28.

17 W. Fang, H. Zhang, J. Yin, B. Yang, Y. Zhang, et al., Hydroxyapatite Crystal Formation in the Presence of Polysaccharide, Cryst. Growth Des., 2016, 16, 1247-1255.

18 S. Murugan and M. Rajan, Greener Synthesis of Nano Hydroxyapatite using Fatty acids template for the application of Tissue Engineering Nano Hydroxyapatite: Fatty acids Synthesis and Characterizations, J. Mol. Pharm. Org. Process Res., 2017, 5, 1, DOI: 10.4172/23299053.1000136.

19 Y. Martínez, L. Xue, G. Liu, B. Peng, W. Yan, D. Más, M. Valdivié, C.-A. A. Hu, W. Ren and Y. Yin, The role of methionine on metabolism, oxidative stress, and diseases, Amino Acids, 2017, 49(12), 1-8.

20 Y. Li and W. Weng, Surface modification of hydroxyapatite by stearic acid: characterization and in vitro behaviors, $J$. Mater. Sci.: Mater. Med., 2008, 19(1), 19-25.

21 S. Koutsopoulos and E. Dalas, The Crystallization of Hydroxyapatite in the Presence of Lysine, J. Colloid Interface Sci., 2000, 231, 207.

22 J. Anita Lett, M. Sundareswari, K. Ravichandran and S. Sagadevan, The Fabrication of Porous Hydroxyapatite Scaffold Using Gaur Gum as A Natural Binder, Dig. J. Nanomater. Biostruct., 2018, 13, 235-243.

23 J. Anita Lett, M. Sundareswari, K. Ravichandran, B. Latha and S. Sagadevan, Fabrication and characterization of porous scaffolds for bone replacements using gum tragacanth, Mater. Sci. Eng., C, 2019, 96, 487-495.

24 A. C. Tas, P. J. Majewski and F. Aldinger, Preparation of Strontium- and Zinc-Doped $\mathrm{LaGaO}_{3}$ Powders via Precipitation in the Presence of Urea and/or Enzyme Urease, J. Am. Ceram. Soc., 2002, 85, 1414-1420.

25 D. P. Suhas, H. M. Jeong, T. M. Aminabhavi and A. V. Raghu, Preparation and Characterization of Novel Polyurethanes Containing 4,40- \{oxy-1,4-diphenyl bis(nitromethylidine)\} diphenol Schiff Base Diol, Polym. Eng. Sci., 2014, 54(1), 2432 .
26 A. V. Raghu, G. Anita, Y. M. Barigaddi, G. S. Gadaginamath and T. M. Aminabhavi, Synthesis and Characterization of Novel Polyurethanes Based on 2,6-Bis(4hydroxybenzylidene) Cyclohexanone Hard Segments, $J$. Appl. Polym. Sci., 2007, 104(1), 81-88.

27 S. Kumar Swain and D. Sarkar, Fabrication, bioactivity, in vitro cytotoxicity and cell viability of cryo-treated nanohydroxyapatite-gelatin-polyvinyl alcohol macroporous scaffold, Journal of Asian Ceramic Societies, 2014, 2, 241-247. 28 A. Wang, L. Dong, H. Yin, H. Wu, Y. Wada, M. Ren, T. Jiang, $\mathrm{X}$. Cheng and $\mathrm{Y}$. $\mathrm{Xu}$, Size-controlled synthesis of hydroxyapatite nanorods by chemical precipitation in the presence of organic modifiers, Mater. Sci. Eng., C, 2007, 27, 4865-4869.

29 D. P. Cistola, J. A. Hamilton, D. Jackson and D. M. Small, Ionization and Phase Behaviour of Fatty Acids in Water: Application of the Gibbs Phase, Rule, Biochemistry, 1988, 27, 1881-1888.

30 Y. M. Z. Ahmed, S. M. El-Sheikh and Z. Zaki, Changes in hydroxyapatite powder properties via heat treatment, Bull. Mater. Sci., 2015, 38, 1807-1819.

31 Z. Sheikh, S. Najeeb, Z. Khurshid, V. Verma, H. Rashid and M. Glogauer, Biodegradable Materials for Bone Repair and Tissue Engineering Applications, Materials, 2015, 8(9), 5744-5794.

32 H. K. Varma and S. S. Babu, Synthesis of calcium phosphate bioceramics by citrate gel pyrolysis method, Ceram. Int., 2005, 31, 109.

33 W. L. Suchanek, P. Shuk, K. Byrappa, R. E. Riman, K. S. Ten Huisen and V. F. Janes, Mechanochemical-hydrothermal synthesis of carbonated apatite powders at room temperature, Biomaterials, 2002, 23, 699.

34 W. E. Klee and G. Engel, Infrared spectra of the phosphate ions in various apatites, J. Inorg. Nucl. Chem., 1970, 32, 1837.

35 H. Li, M. Zhu, L. Li and C. Zhou, Processing of nanocrystalline hydroxyapatite particles via reverse microemulsions, J. Mater. Sci., 2008, 43, 384-389.

36 Y. Zhang and J. Lu, A simple method to tailor spherical nanocrystal hydroxyapatite at low temperature, J. Nanopart. Res., 2007, 9, 589-594.

37 Y. Cai, Y. Liu, W. Yan, Q. Hu, J. Tao, M. Zhang, Z. Shi and R. Tang, Role of hydroxyapatite nanoparticle size in bone cell proliferation, J. Mater. Chem., 2007, 17, 3780-3787.

38 R. Samavini, C. Sandaruwan, M. De Silva, G. Priyadarshana, N. Kottegoda and V. Karunaratne, Effect of Citric Acid Surface Modification on Solubility of Hydroxyapatite Nanoparticles, J. Agric. Food Chem., 2018, 66(13), 3330-3337.

39 A. Wang, H. Yin, L. Dong, H. Wu, M. Ren, T. Jiang, X. Cheng and $\mathrm{Y}$. Xu, Size-controlled synthesis of hydroxyapatite nanorods in the presence of organic modifiers, Mater. Lett., 2007, 61, 2084-2088.

40 H.-b. Zhang, K.-c. Zhou, L. I. Zhi-you, H. Su-ping and Y.-z. Zhao, Morphologies of hydroxyapatite nanoparticles adjusted by organic additives in hydrothermal synthesis, $J$. Cent. South Univ. Technol., 2009, 16, 0871-0875.

41 N. Puvvada, P. Kumar Panigrahi, H. Kalita, K. R. Chakraborty and A. Pathak, Effect of temperature on morphology of 
triethanolamine - assisted synthesized HAp, Appl. Nanosci., 2013, 3, 203-209.

42 G. Fotakis and J. A. Timbrell, In vitro cytotoxicity assays: comparison of LDH, neutral red, MTT and protein assay in hepatoma cell lines following exposure to cadmium chloride, Toxicol. Lett., 2006, 160(2), 171-177.

43 A. F. Kamal, D. Iskandriati, I. H. Dilogo, N. C. Siregar, E. U. Hutagalung, R. Susworo, A. A. Yusuf and A. Bachtiar, Biocompatibility of various hydroxyapatite scaffolds evaluated by proliferation of rat's bone marrow mesenchymal stem cells: an in vitro study, Med. J. Indones., 2013, 22, 202-208.

44 G. S. Kaliaraj, M. Bavanilathamuthiah, K. Kirubaharan, D. Ramachandran, T. Dharini, K. Viswanathan and V. Vishwakarma, Bio-inspired YSZ coated titanium by EBPVD for biomedical applications, Surf. Coat. Technol., 2016, 307, 227-233.

45 M. Indhumathy, Bavanilathamuthiah and C. G. Malar, Anticancer activity of Zingiber officinale bound dendrimera in vitro analysis, Int. J. Drug Discovery, 2014, 5(3), 77-81.

46 P. V. Kulkarni, C. A. Roney, P. P. Antich, F. J. Bonte, A. V. Raghu and T. M. Aminabhavi, Quinoline-n-butyl cyanoacrylate based nanoparticles for targeting for the diagnosis of Alzheimer's disease, Adv. Rev., 2010, 2, 35-47.

47 A. V. Raghu, S. Gadaginamath, N. Mathew, S. B. Halligudi and T. M. Aminabhavi, Synthesis, Characterization, and Acoustic Properties of New Soluble Polyurethanes Based on 2,20- [1,4-Phenylenebis (nitrilomethylylidene) diphenol] and 2,20- [4,40-Methylene-di-2-methylphenylene-1,10- bis (nitrilomethylylidene)] diphenol, J. Appl. Polym. Sci., 2007, 106(1), 299-308.

48 X. Lian, H. Liuc, X. Wanga, S. Xua, F. Cuia and X. Bai, Antibacterial and biocompatible properties of vancomycinloaded nano-hydroxyapatite/collagen/poly (lactic acid) bone substitute, Prog. Nat. Sci.: Mater. Int., 2013, 23(6), 549-556.

49 M. S. Feiz and A. Meshkini, Targeted delivery of adenosine 5 -triphosphate using chitosan-coated mesoporous hydroxyapatite: a theranostic pH-sensitive nanoplatform with enhanced anti-cancer effect, Int. J. Biol. Macromol., 2018, S0141-8130(18), 33138-6.

50 Z. N. Al-Sokanee, A. A. H. Toabi, M. J. Al-assadi and E. A. S. Alassadi, The Drug Release Study of Ceftriaxone from Porous Hydroxyapatite Scaffolds, AAPS PharmSciTech, 2009, 10(3), 772-779. 